\title{
PREPARATION AND CHARACTERIZATION OF CHITOSAN/REGENERATED SILK FIBROIN (CS/RSF) FILMS AS A BIOMATERIAL FOR CONTACT LENSES-BASED OPHTHALMIC DRUG DELIVERY SYSTEM
}

\author{
RACHASIT JEENCHAM ${ }^{a, b}$, MANOTE SUTHEERAWATTANANONDAc, WAREE TIYABOONCHAI ${ }^{a, b, d{ }^{*}}$
}

aFaculty of Pharmaceutical Sciences, Naresuan University, Phitsanulok 65000, Thailand, bThe Center of Excellence for Innovation in Chemistry (PERCH-CIC), Commission on Higher Education, Ministry of Education, Bangkok 10400, Thailand, 'Institute of Agricultural Technology, Suranaree University of Technology, Nakhon Ratchasima 30000, Thailand, dThe Center of Excellence in Medical Biotechnology, Naresuan University, Phitsanulok 65000, Thailand

Email: wareet@nu.ac.th

Received: 29 Mar 2019, Revised and Accepted: 24 May 2019

\section{ABSTRACT}

Objective: The aim of this study was to develop chitosan/regenerated silk fibroin (CS/RSF) films as a biomaterial for contact lenses-based ophthalmic drug delivery system.

Methods: CS/RSF films were prepared with polyethylene glycol 400 as a plasticizer by using a film casting technique. Their physicochemical properties were investigated by measuring various properties such as thickness, morphology, chemical interaction, light transparency, mechanical properties, water content, oxygen permeability, thermal properties and enzyme degradation. In addition, cytotoxicity was also studied.

Results: At optimal preparation conditions, CS/RSF films showed smooth surfaces with highly visible light transparency of $>90 \%$, which meet the visual requirement. CS/RSF films showed high water content, 59-65\% by weight, and their Young's modulus and elongation at break was in the range of 3.8-6 N/ $\mathrm{mm}^{2}$ and $113-135 \%$, respectively. The CS/RSF films also could be sterilized by autoclave method as they possessed high thermal decomposition temperature of $>260^{\circ} \mathrm{C}$ which can be confirmed by both differential scanning calorimetry and thermogravimetric analysis. In addition, CS/RSF films showed no degradation in stimulated tear fluid containing lysozyme for $7 \mathrm{~d}$ and showed no cytotoxicity by MTT assay.

Conclusion: CS/RSF films showed excellent physicochemical properties and non-cytotoxicity indicating their promising potential use as a biomaterial for contact lenses-based ophthalmic drug delivery system.

Keywords: Chitosan, Regenerated silk fibroin, Films, Contact lenses, Ophthalmic drug delivery system, Cytotoxicity

(C) 2019 The Authors. Published by Innovare Academic Sciences Pvt Ltd. This is an open access article under the CC BY license (http://creativecommons.org/licenses/by/4.0/) DOI: http://dx.doi.org/10.22159/ijap.2019v11i4.33283

\section{INTRODUCTION}

Topical drug administration is a common approach to treat ocular disorders. Currently, more than $90 \%$ of marketed topical eye drops are in the form of solutions and suspensions because of their convenience and ease of administration [1-3]. However, eye drops are notorious for poor ocular bioavailability with less than $5 \%$ of administered drugs entering the anterior chamber and reaching the intraocular tissues [2, 4-6]. A large part of the drugs is lost into the systemic circulation by blinking, rapid tear turnover rate and drainage into the nasal cavity. To maintain sustained therapeutic drug levels, frequent administration or large doses are often required. Consequently, this reduces patient compliance, increases local side effects, and also results in pronounced systemic exposure $[2,7-9]$. Recently, daily disposable contact lenses-based ophthalmic drug delivery systems have been proposed as alternative ophthalmic drug delivery systems for increased ocular bioavailability [10-14]. These approaches can be administered without any surgery and have been demonstrated to produce sustained drug release for a prolonged period by increasing the residence time of the drug on the ocular surface [12, 15-17]. The benefit of daily disposable therapeutic contact lenses would be the delivery of the correct medication dosage at an approximately constant rate, thereby eliminating the frequent application of topical eye drops and, more importantly, leading to more benefits to the patient with substantially increased efficacy. Typically, commercial daily disposable contact lenses are usually made from synthetic polymers, such as poly (2-hydroxyethyl methacrylate) (pHEMA)-based hydrogel and silicone based-hydrogel $(\mathrm{SiH})$. pHEMA-based hydrogel contact lenses provide high water content of up to $80 \%$ and softness that promotes comfortable wearing. Their main disadvantages are low strength [18-21]. SiH contact lenses, in contrast, have high oxygen permeability and low adhesion to the bacteria, but they are low in water content with a hydration ability of $<45 \%$ [20-25].
To overcome the limitation of synthetic polymer-based contact lenses, we have proposed natural polymers as a potential biomaterial for contact lenses. This is due to their advantages of nontoxicity, good biocompatibility, low inflammatory, high oxygen permeability, high optical transparency, high wettability, and good chemical and mechanical stabilities that could meet the required properties of daily disposable contact lenses. Furthermore, they can be used as daily disposable therapeutic contact lenses [26-39]. Chitosan (CS) and regenerated silk fibroin (RSF) are natural polymers of interest. CS is a natural polycationic linear polysaccharide derived from the deacetylation of chitin [40]. RSF, which is derived from degumming of the Bombyx mori cocoons and dissolution of silk fibroin respectively, is a protein mainly comprised of amino acids glycine, alanine, and serine [41, 42]. CS films showed good flexibility, high light transparency and high water content but it is highly sensitive to lysozyme degradation [32-35, 43]. RSF films offer the advantages of high oxygen permeability, non-toxicity, excellent biocompatibility, and also excellent wound healing properties, but it is quite brittle [26-31]. Therefore, the blending between CS and RSF is a possible solution to improve the properties of films for creating the materials of daily disposable therapeutic contact lenses. Moreover, the blending of CS with RSF shows good compatibility between two different materials by hydrogen bonding interaction $[36,40]$.

Nowadays, there are very few reports on therapeutic contact lenses using a combination of natural polymers [35, 40], especially; there are no reports on the combination of CS/RSF for contact lenses. Therefore, the purpose of this study was to develop CS/RSF films as the biomaterials for contact lenses-based ophthalmic drug delivery system. The physicochemical properties of CS/RSF films were investigated by measuring various properties such as thickness, morphology, chemical interaction, light transparency, mechanical properties, water content, oxygen permeability, thermal properties and enzyme degradation. In addition, cytotoxicity was also studied. 


\section{MATERIALS AND METHODS}

\section{Materials}

CS $(>90 \%$ deacetylation with a mean molecular weight of $890 \mathrm{kDa}$ ) was obtained from Marine Bio-Resources Co., Ltd (Samutsakhon, Thailand). Bombyx mori raw silk yarns were purchased from Badin Thai-Silk Korat Co., Ltd (Nakhon Ratchasima, Thailand). Polyethylene glycol 400 (PEG400) was purchased from Namsiang trading Co., Ltd (Bangkok, Thailand). Snakeskin pleated dialysis tube with MWCO at 10,000 Daltons was obtained from Thermo Scientific Inc. (Illinois, USA). All other chemicals and solvents were of analytical grade. Keratinocyte serum-free medium (K-SFM) with bovine pituitary extract (BPE), and recombinant human epidermal growth factor (EGF) were purchased from Thermo Fisher Scientific Co., Ltd. (Bangkok, Thailand). Telomerase-immortalized human corneal epithelial cells line (HCECs) were a gift from Associate Professor Dr. Sangly P. Srinivas (School of Optometry, Indiana University, USA).

\section{Preparation of RSF}

RSF was prepared according to Yamada et al. (2001) and Ajisawa (1998) [44, 45]. Briefly, raw silk yarns of Bombyx mori were degummed twice by boiling in a $0.5 \%(\mathrm{w} / \mathrm{v})$ sodium carbonate solution for one hour to remove sericin. Then, the silk yarns were washed three times with warm reverse osmosis (RO) water and dried overnight at $40{ }^{\circ} \mathrm{C}$. The resulting degummed silk yarns were heated at $85-90{ }^{\circ} \mathrm{C}$ in a solution of $\mathrm{CaCl}_{2}: \mathrm{H}_{2} \mathrm{O}: \mathrm{Ca}\left(\mathrm{No}_{3}\right)_{2}: \mathrm{EtOH}$ at 30:5:45:20 in gram ratio until a gel-like solution was formed. Next, the resultant gel is dialyzed (using a snakeskin pleated dialysis tube having a 10,000 MWCO) against RO water at room temperature for 3 $\mathrm{d}$ to remove residual salts, then centrifuged at $15300 \times \mathrm{g}$ for $30 \mathrm{~min}$ to remove foreign particles. The RSF solution was lyophilized and kept in sealed plastic bags at $-20^{\circ} \mathrm{C}$ until use.

\section{Preparation of CS/RSF films}

CS/RSF films were prepared by a casting method [37]. Briefly, 2\% $(\mathrm{w} / \mathrm{v}) \mathrm{RSF}$ aqueous solution, $2 \%(\mathrm{w} / \mathrm{v})$ of CS solution, dissolved in $2 \%(\mathrm{v} / \mathrm{v}$ ) acetic acid and PEG400 $25 \% \mathrm{w} / \mathrm{w}$ of polymer matrix were mixed using magnetic stirrer at $200 \mathrm{rpm}$ for $30 \mathrm{~min}$. The CS/RSF ratios were varied as $100 / 0,90 / 10,80 / 20$ and $70 / 30(\mathrm{w} / \mathrm{w})$. The mixtures were then poured onto the polystyrene plates and dried in an oven at $40{ }^{\circ} \mathrm{C}$ until completely dried. The dried films were immersed in $1 \mathrm{M} \mathrm{NaOH}$ solution for $15 \mathrm{~min}$, and then repeatedly rinsed with RO water until a neutral $\mathrm{pH}$ was obtained. The films were then soaked in $0.01 \mathrm{M}$ phosphate buffer saline (PBS) solution, $\mathrm{pH} 7.4$ for $24 \mathrm{~h}$ and autoclaved at $121^{\circ} \mathrm{C}$ and $15 \mathrm{psi}$ for $20 \mathrm{~min}$. The autoclaved CS/RSF films were dried at room temperature and further stored in desiccators until used. All samples were prepared in triplicate.

\section{Thickness measurements}

The CS/RSF films thickness was measured with a thickness gauge (Mitutoyo 7301 Dial Thickness Gage, Kanagawa, Japan). The dried films were rehydrated by soaking them in $0.01 \mathrm{M}$ phosphate buffer saline (PBS), pH 7.4 for $24 \mathrm{~h}$. Measurements were taken at the center and at four positions around the perimeter of the hydrated film and then the average thickness of films was calculated [46].

\section{Morphology}

A scanning electron microscope (SEM, Carl Zeiss AURIGA $\AA$, Thuringia, Germany) was employed to examine the morphology of surface and cross-section of RSF/CS films. The samples were sputter-coated with gold by plasma in order to minimize electron charging on the surface and to obtain fine images. Acceleration voltage of $5 \mathrm{kV}$ was used to collect SEM images of the samples.

\section{Fourier transform infrared spectroscopy (FTIR)}

FTIR was performed to investigate the chemical interaction of CS and RSF in the blended films using a Tensor 27 FTIR spectrometer (Bruker Optics, Ettlingen, Germany). The infrared spectra of samples were recorded at room temperature in the spectral region of 4000$500 \mathrm{~cm}^{-1}[36]$.

\section{Light transparency}

The light transparency of CS/RSF films were determined using UVVIS spectrophotometer (Genesys 10S, Thermo scientific, Wisconsin, USA). A dried film was rehydrated by soaking it in $0.01 \mathrm{M}$ PBS, $\mathrm{pH} 7.4$ for $24 \mathrm{~h}$. Then the hydrated film with an average thickness of $0.09 \mathrm{~mm}$ was mounted on the outer surface of a quartz cuvette. The cuvette was placed in the spectrophotometer and the light transparency was measured at 280-780 nm [47].

\section{Mechanical properties}

The Young's modulus and elongation at break of the CS/RSF films were determined according to ASTM D882-12 using a texture analyzer (TA. XT-PLUS, London, UK) with a load cell of $5 \mathrm{~kg}$, a crosshead speed of $20 \mathrm{~mm} / \mathrm{min}$, and a gauge length of $10 \mathrm{~mm}$ [48]. A dried film was rehydrated by soaking it in 0.01M PBS, pH 7.4 for 24 $\mathrm{h}$, and then the hydrated film with a width of $3 \mathrm{~mm}$ and thickness of $0.09 \mathrm{~mm}$ was measured using the texture analyzer.

\section{Water content}

The CS/RSF films were soaked in 0.01M PBS, pH 7.4 for $24 \mathrm{~h}$, and then water content of films was measured using a moisture analyzer (Sartorius MA 30, Sartorius lab instruments GmbH and Co. KG, Lower Saxony, Germany). The rehydrated film was weighed for its initial weight (Wwet). After that, the rehydrated film was dried at $105^{\circ} \mathrm{C}$ and weighed several times until the film's weight was constant (Wdried) [49]. The water content was calculated as shown in the following equation (1)

$$
\text { Water content }(\%)=\frac{\left(\mathrm{W}_{\text {wet }}-\mathrm{W}_{\text {dried }}\right)}{\mathrm{W}_{\text {wet }}} \times 100 \ldots
$$

\section{Thermal properties}

Differential scanning calorimetry (DSC) was performed to determine the thermal properties of the CS/RSF films using DSC 3+STAR System (Mettler Toledo (Thailand), Bangkok, Thailand). Samples were heated from $-20^{\circ} \mathrm{C}$ to $400{ }^{\circ} \mathrm{C}$ at a heating rate of $20^{\circ} \mathrm{C} /$ min under a nitrogen atmosphere with a flow rate of $50 \mathrm{ml} / \mathrm{min}$ [36]. Thermogravimetric analysis (TGA) was performed using TGA/DSC 3+STAR System (Mettler Toledo (Thailand), Bangkok, Thailand). The thermal decomposition temperature of each sample was examined under a nitrogen atmosphere with a flow rate of $50 \mathrm{ml} / \mathrm{min}$, in a temperature range of $30-600{ }^{\circ} \mathrm{C}$ and at a heating rate of $20^{\circ} \mathrm{C} / \mathrm{min}$ [36].

\section{Ion permeability}

The ion permeability was determined using a homemade horizontal diffusion cell, with an aperture a diameter of $35 \mathrm{~mm}$, at $34 \pm 1{ }^{\circ} \mathrm{C}$. The receiving chamber was filled with $35 \mathrm{ml}$ of deionized (DI) water. After soaking in DI water for $24 \mathrm{~h}$, a hydrated film, $0.09 \mathrm{~mm}$ in thickness, was placed between the two compartments of the diffusion cell and then the donor chamber was filled with $18 \mathrm{ml}$ of $154 \mathrm{mmol} \mathrm{NaCl}$ solution. The conductivity of the solution in the receiving chamber was measured at time intervals by a conduct meter (Model 712 Conductometer, Metrohm UK Ltd., Cheshire, UK). The conductivity was converted to ion concentration using the calibration curve of $\mathrm{NaCl}$ solution with a concentration range of 10-60 mmol. The ion concentration was plot as a function of time. Then, the apparent ion permeability was calculated using a slope (F) at steady state (dc/dt) following Fick's law as shown in the following equation (2) $[47,50]$.

$$
\text { Apparent ion permeability }\left(\mathrm{mm}^{2} / \mathrm{min}\right)=\left(\frac{\mathrm{F} \times \mathrm{V}}{\mathrm{A}}\right) /\left(\frac{\mathrm{C}_{0}}{\mathrm{~T}}\right) \text {... }
$$

Where $\mathrm{V}$ is the volume of the receiving chamber solution, $\mathrm{A}$ is the area of the tested film, $\mathrm{C}_{0}$ is the initial $\mathrm{NaCl}$ concentration in the donor, and $\mathrm{T}$ is the film thickness.

\section{Oxygen permeability}

CS/RSF contact lenses for oxygen permeability testing were prepared by spinning casting method in an oven at $40{ }^{\circ} \mathrm{C}$ until completely dried, The oxygen permeability of hydrated CS/RSF contact lenses, $0.2 \mathrm{~mm}$ of center thickness, were measured according to ISO $18369-4\left(35^{\circ} \mathrm{C}\right.$ and $>98 \%$ relative humidity) using the polarographic amplifier (Model 201T Permeometer, Createch/Rehder development. CO., Indiana, USA). 


\section{In vitro enzymatic degradation}

The degradation of CS/RSF films was analyzed following their incubation at $34 \pm 1{ }^{\circ} \mathrm{C}$ in stimulated tear fluid (STF) containing lysozyme $1 \mathrm{mg} / \mathrm{ml} \mathrm{(pH} \mathrm{7.4).} \mathrm{The} \mathrm{compositions} \mathrm{of} \mathrm{STF} \mathrm{were} \mathrm{sodium}$ chloride $0.67 \mathrm{~g}$, sodium bicarbonate $0.2 \mathrm{~g}$, calcium chloride $2 \mathrm{H}_{2} \mathrm{O}$ $0.008 \mathrm{~g}$, and deionized water added to $100 \mathrm{~g}$. The film $\left(2 \times 2 \mathrm{~cm}^{2}\right)$ after autoclaving and drying were weighed (initial weight, $\mathrm{W}_{0}$ ). The films were immersed in $2 \mathrm{ml}$ of STF containing lysozyme for 2, 5, 7, and $14 \mathrm{~d}$. After that, the films were dried at $60{ }^{\circ} \mathrm{C}$ overnight and weighed after degradation $\left(\mathrm{W}_{1}\right)$. The percentage of the remaining weight was calculated as shown in the following equation (3) [33, 51-53].

$$
\text { Remaining weight }(\%)=\frac{\mathrm{W}_{1}}{\mathrm{~W}_{0}} \times 100 \ldots \ldots . .(3)
$$

\section{Cytotoxicity study}

CS/RSF films cytotoxicity was determined by telomerase-immortalized human corneal epithelial cells line (HCECs) viability. The HCECs were seeded onto 96-well plates at $1.5 \times 10^{4}$ cells per well in $100 \mu$ of cell culture medium and incubated at $37^{\circ} \mathrm{C}, 5 \% \mathrm{CO}^{2}$ until reaching $\sim 90 \%$ of cell confluence ( $3 \mathrm{~d}$ ). The RSF/CS films, after soaking with PBS for $24 \mathrm{~h}$, were cut into the same size of 96-well plates and were then autoclaved. Then, the films were placed gently on HCECs in 96-well plates and incubated for up to $24 \mathrm{~h}$ at $37{ }^{\circ} \mathrm{C}, 5 \% \mathrm{CO}^{2}$. After $24 \mathrm{~h}$, the films were carefully removed from the wells. Then, the cells were washed with PBS twice, and $100 \mu \mathrm{l}$ of 3-(4, 5-Dimethylthiazol-2-yl)-2, 5Diphenyltetrazolium Bromide (MTT) solution $(0.5 \mathrm{mg} \mathrm{MTT} / \mathrm{ml}$ of medium) was added. After a $2 \mathrm{~h}$ reaction time, MTT formazan was extracted with dimethyl sulfoxide (DMSO) for $10 \mathrm{~min}$ and the absorbance of the extract was measured at $595 \mathrm{~nm}$ with a microplate reader (Synergy ${ }^{\mathrm{TM}}$ H1, BioTek Instruments, Inc., Vermont, USA) [54]. All results were expressed as relative viability compared to cells grown in the absence of a film (control). The ratio (\%) of MTT formazan absorbance for each sample to the absorbance of MTT formazan for control represented cell viability using the following formula (4).

$$
\text { Cell viability }(\%)=\frac{\text { Absorbance of sample }}{\text { Absorbance of control }} \times 100 \ldots
$$

\section{Statistical analysis}

The results were expressed as mean \pm standard deviation (SD). For all comparisons, statistical significant differences were analyzed with paired t-test or one-way ANOVA followed by Tukey's post hoc test, and $\mathrm{P}<0.05$ was considered statistically significant.

\section{RESULTS AND DISCUSSION}

The PEG 400 content, $25 \%$ by weight of polymer content, and the 15 min $\mathrm{NaOH}$ treatment were selected based on the preliminary study. In the preliminary study, CS/RSF films prepared with PEG400 as a plasticizer were successfully developed. However, without $\mathrm{NaOH}$ treatment, they were extremely weak and brittle. On the other hand, with 15 min $\mathrm{NaOH}$ treatment, CS/RSF films showed high strength with homogeneous films. This is due to $\mathrm{NaOH}$ allowing new hydrogen bond formation which caused larger anhydrous crystal size and more compact structure in the films [55]. In addition, the film prepared with PEG400 at $25 \%$ by weight of polymer content showed high oxygen permeability. Therefore, all the prepared films were composed of PEG400 25\% w/w with 15 min NaOH treatment. Moreover, the blended films were prepared covering the whole range of CS/RSF weight ratio of $100 / 0$ to $0 / 100(w / w)$. Unfortunately, the pure RSF film and CS/RSF films at ratios of 30/70, $20 / 80$, and $10 / 90(\mathrm{w} / \mathrm{w})$ were extremely brittle and could not be handled. In contrast, when increasing the CS content, CS/RSF ratios of $100 / 0,90 / 10,80 / 20,70 / 30,60 / 40,50 / 50$, and $40 / 60(\mathrm{w} / \mathrm{w})$, the obtained films showed to be non-brittle and were strong enough to handle without deformation. However, CS/RSF films at ratios of $60 / 40,50 / 50$, and $40 / 60(\mathrm{w} / \mathrm{w})$ showed visible light transparency of less than $90 \%$, which did not satisfy the visual requirements. Typically, the visible light transparency of contact lenses should be more than $90 \%$ [56]. Therefore, only CS/RSF films at ratios of 100/0, 90/10, $80 / 20$, and $70 / 30(\mathrm{w} / \mathrm{w})$ were selected to be further studied as they manifested high tensile strength with visible light transparency of $>90 \%$ which is similar to commercial contact lenses [47].

\section{Appearances and morphology of CS/RSF films}

The prepared CS/RSF films at ratios of 100/0, 90/10, 80/20 and $70 / 30(\mathrm{w} / \mathrm{w})$ were uniformly light transparent, non-brittle and were strong enough to handle without deformation. Typically, commercial contact lenses have thickness of 0.05-0.2 mm [20, 57]. All prepared CS/RSF films showed no significant difference in thickness of $0.09 \pm 0.01 \mathrm{~mm}$, indicating they were suitable for contact lenses. SEM micrographs of topical surface of all CS/RSF films showed smooth surfaces without phase separation. Moreover, their cross-sections exhibited homogenous blending between CS and RSF without obvious phase disengagement as shown in table 1.

\section{FTIR}

FTIR spectra of RSF film, CS film, PEG400, and CS/RSF films, were shown in fig. 1. The RSF film without PEG400 prepared with acidic condition showed silk II conformation as evident from the peak absorption bands at $1620 \mathrm{~cm}^{-1}$ (amide I, C=0 stretching) and $1514 \mathrm{~cm}^{-1}$ (amide II, N-H bending and C-H stretching) corresponding to the $\beta$ sheet conformation indicating crystalline portion $[58,59]$. Although, amide III absorption band ( $\mathrm{C}-\mathrm{N}$ stretching and $\mathrm{C}=\mathrm{O}$ bending) was observed at $1231 \mathrm{~cm}^{-1}$, silk I conformation (random coil), indicating amorphous region $[58,60,61]$. The low water solubility of the RSF film indicated the predominance of silk II structure. This was in agreement with Kweon et al., (2001) who verified that a more stable RSF structure could be induced by acetic acid [62].

The CS film without PEG400 exhibited absorption band at $1634 \mathrm{~cm}^{-1}$ (C=0 stretching), $1537 \mathrm{~cm}^{-1}\left(\mathrm{NH}_{2}\right.$ stretching), $1256 \mathrm{~cm}^{-1}(\mathrm{O}-\mathrm{H}$ bending), $1065 \mathrm{~cm}^{-1}$ and $1020 \mathrm{~cm}^{-1}$ (C-0 stretching) [36, 46, 62]. In addition, PEG400 showed characteristic absorption band at 3454 $\mathrm{cm}^{-1}$ (O-H stretching), $2866 \mathrm{~cm}^{-1}$ (C-H stretching) and 1095 (C-O-C stretching) [63]. Interestingly, 100CS/0RSF film showed $\mathrm{NH}_{2}$ peak shift from 1537 to $1541 \mathrm{~cm}^{-1}$ and $0-\mathrm{H}$ peak shift from 1256 to 1252 $\mathrm{cm}^{-1}$ suggesting H-bonding between-OH of PEG400 with- $\mathrm{NH}_{2}$ or-OH of CS.

The FTIR analysis of CS/RSF blended films suggested intermolecular H-bonding between CS and RSF indicating a good compatibility between CS and RSF. For example, the FTIR spectra of 70CS/30RSF film revealed the $\mathrm{NH}_{2}$ peak of CS was shifted from 1541 to $1531 \mathrm{~cm}^{-1}$ and $\mathrm{C}=0$ peak of RSF was shifted from 1620 to $1622 \mathrm{~cm}^{-1}$. The good compatibility of the blended films was in agreement with SEM micrographs (table 1) confirming a homogeneous morphology without phase separation of the blended films.

\section{Light transparency of CS/RSF films}

The light transparency of blended films is an important property of contact lenses. The optical transmittance spectra in the range 280$780 \mathrm{~nm}$ of CS/RSF films were displayed in fig. 2, while the mean light transparency of each spectral range was shown in table 2. Typically, the visible light transparency (381-780 nm) of contact lenses should be more than $90 \%$ [56]. All CS/RSF films showed excellent visible light transparency of $>90 \%$, which meet the visual requirement, indicating good compatibility of the blended film. According to the American National Standards Institute of Z80.20 standard, contact lenses shall satisfy Class II UV blocking, which transmittance for UV-B (280-315 nm) and UV-A (316-380 nm) less than $5 \%$ and $30 \%$, respectively. Although UV-B and UVA transmittance of all prepared CS/RSF films did not meet the Class II UV blocking standard. However, all films showed significant protection against UV-B and UV-A, especially when increasing the RSF content. 100CS/0RSF film showed UV-B and UV-A transmittance of $27 \%$ and $58 \%$ respectively while $70 \mathrm{CS} / 30 \mathrm{RSF}$ was reduced to $12 \%$ and $50 \%$, respectively. In addition, the blue visible light is considered unsafe to the eyes. It can be divided into the shortwavelength blue region (SWB, 381-460 nm) and the longwavelength blue region (LWB, 461-500 nm). Similarly to UV blocking ability, all films showed the ability to reduce blue light transmittance suggesting some protection against blue light, particularly when the amount of RSF was increased. 100CS/0RSF film showed SWB transmittance of $88 \%$, while 70CS/30RSF was reduced to $80 \%$. These results suggested that the CS/RSF blended films showed greater potential in the protection from UV-B, UV-A, and blue light than CS film. 
Table 1: SEM micrographs of surface and cross-section of CS/RSF films ( $\times 1000$ magnification)
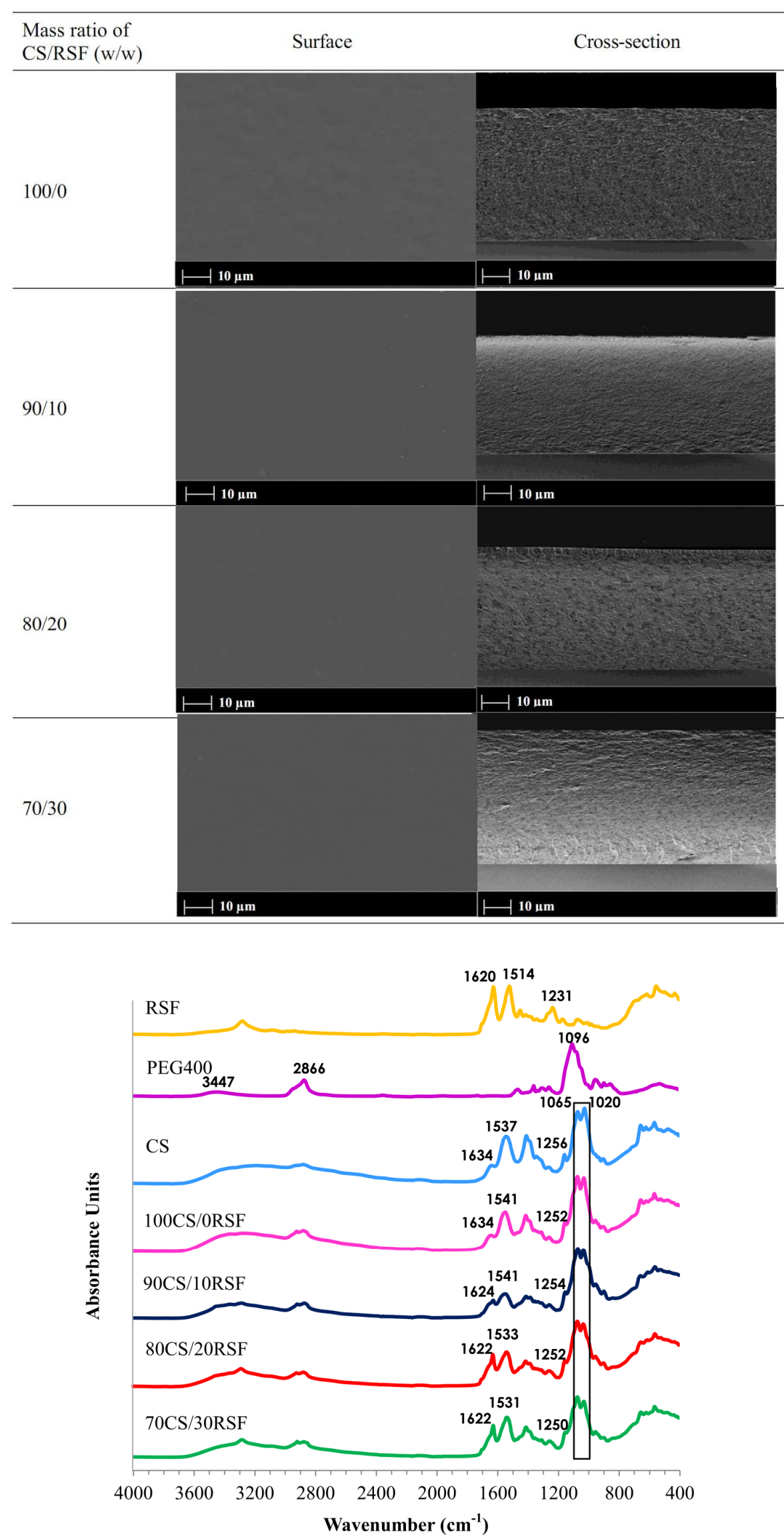

Fig. 1: FTIR spectra of RSF film, PEG400, CS film and CS/RSF films with indicated blend ratios 
Table 2: Light transparency of CS/RSF films

\begin{tabular}{|c|c|c|c|c|c|}
\hline \multirow[t]{3}{*}{ Mass ratio of CS/RSF (w/w) } & \multicolumn{5}{|c|}{ Light transparency $(\%) \pm S D$} \\
\hline & UV-B & UV-A & SWB & LWB & Visible \\
\hline & $(280-315 \mathrm{~nm})$ & $(316-380 \mathrm{~nm})$ & $(381-460 \mathrm{~nm})$ & $(461-500 \mathrm{~nm})$ & $(381-780 \mathrm{~nm})$ \\
\hline $100 / 0$ & $27 \pm 2$ & $58 \pm 2$ & $88 \pm 1$ & $95 \pm 1$ & $95 \pm 1$ \\
\hline $90 / 10$ & $17 \pm 0$ & $52 \pm 0$ & $83 \pm 1$ & $91 \pm 1$ & $92 \pm 1$ \\
\hline $80 / 20$ & $10 \pm 1$ & $48 \pm 1$ & $82 \pm 0$ & $90 \pm 0$ & $91 \pm 0$ \\
\hline $70 / 30$ & $12 \pm 2$ & $50 \pm 3$ & $80 \pm 2$ & $88 \pm 2$ & $90 \pm 2$ \\
\hline
\end{tabular}

SD: standard deviation, $n=3$

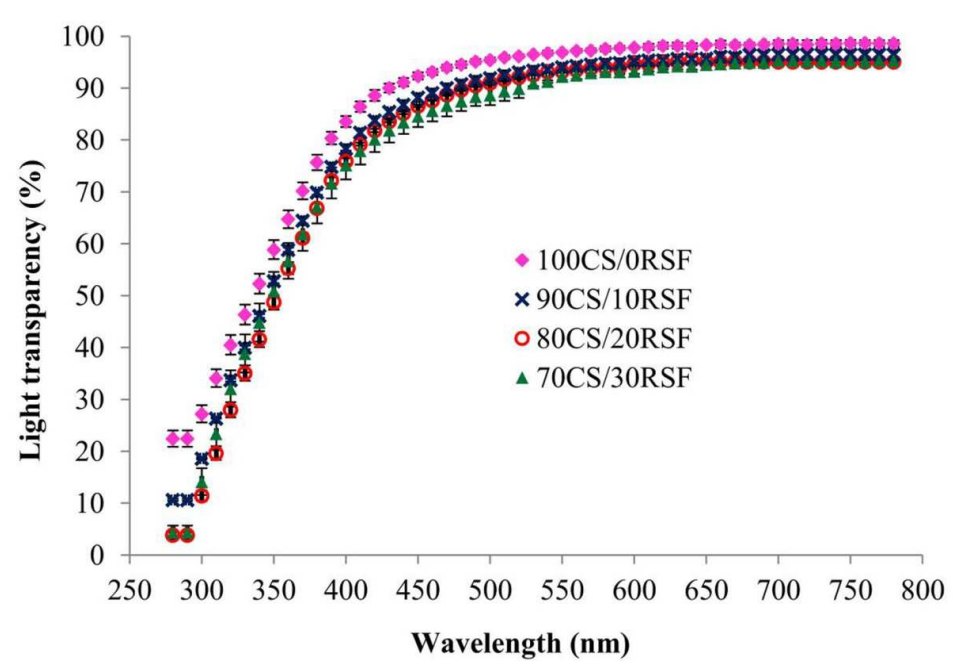

Fig. 2: Light transparency of CS/RSF films with indicated blend ratios, error bars indicate SD for $n=3$

\section{Mechanical properties of CS/RSF films}

The mechanical properties of contact lenses are important considerations with respect to durability and resistance to damage during handling. The stiffness and flexibility of contact lenses are expressed by Young's modulus and elongation at break, respectively. The Young's modulus of CS/RSF films was decreased by increasing RSF content, table 3. 100CS/0RSF film showed Young's modulus of 6 $\mathrm{N} / \mathrm{mm}^{2}$, while $70 \mathrm{CS} / 30 \mathrm{RSF}$ was reduced to $3.8 \mathrm{~N} / \mathrm{mm}^{2}$. The maximum Young's modulus of the various commercial soft contact lenses materials are reported to be at $1.5 \mathrm{~N} / \mathrm{mm}^{2}[22,23,48,64]$. Clearly, the stiffness of CS/RSF films was slightly higher suggesting a more stiffness and thus are easier to handle and less likely to fold in on itself. Similarly, the RSF content affected the elongation at break. The elongations at break of 100CS/0RSF and 70CS/30RSF films were 135 and 113\%, respectively (table 3). Nevertheless, all prepared blended films possessed the elongation at break of $>50 \%$ which are considered to satisfy the flexibility requirement [48].

\section{Water content of CS/RSF films}

Water content is one of the key parameters to determine the comfort of wearing contact lenses wearing. Contact lenses with high water content would offer greater softness and comfortable wearing. According to FDA's classification, soft contact lenses with the water content of $<50 \%$ by weight is considered as "low water content", while those with $>50 \%$ by weight is considered as "high water content". All prepared CS/RSF films showed high water content (59 to $65 \%$ by weight) as shown in table 3 . Nevertheless, the water content of CS/RSF films was slightly decreased as the content of silk fibroin increased. This phenomenon could be explained by the intermolecular hydrogen bonds between CS and RSF molecules, resulting in the reduced interaction between $\mathrm{CS}$ and water.

Table 3: Mechanical properties and water content of CS/RSF films

\begin{tabular}{llll}
\hline Mass ratio of $\mathbf{C S} / \mathbf{R S F}(\mathbf{w} / \mathbf{w})$ & Young's modulus $\left(\mathbf{N} / \mathbf{m m}^{2}\right) \pm \mathbf{S D}$ & Elongation at break (\%) $\mathbf{S S D}$ & Water content (\%) \pm SD \\
\hline $100 / 0$ & $6.0 \pm 1.2$ & $135 \pm 17$ & $65 \pm 1.34$ \\
$90 / 10$ & $5.4 \pm 0.6$ & $116 \pm 28$ & $62 \pm 1.38$ \\
$80 / 20$ & $4.6 \pm 1.1$ & $111 \pm 26$ & $59 \pm 1.35$ \\
$70 / 30$ & $3.8 \pm 0.5$ & $113 \pm 13$ & $59 \pm 0.92$ \\
\hline
\end{tabular}

SD: standard deviation, $n=3$

\section{Thermal properties of CS/RSF films}

Thermal properties of CS/RSF films were investigated by DSC measurement as shown in fig. 3. Water evaporation temperature, glass transition temperature (Tg), thermal decomposition temperature were investigated. A broad endothermic peak below
$110{ }^{\circ} \mathrm{C}$ observed in all CS/RSF films was attributed to moisture evaporation. With increasing RSF content, the height and area under endothermic peak were decreased indicating the reduction of moisture in the films. This observation correlated to the water content of the film, the water content of CS/RSF films decreased with increasing RSF content, table 3. 


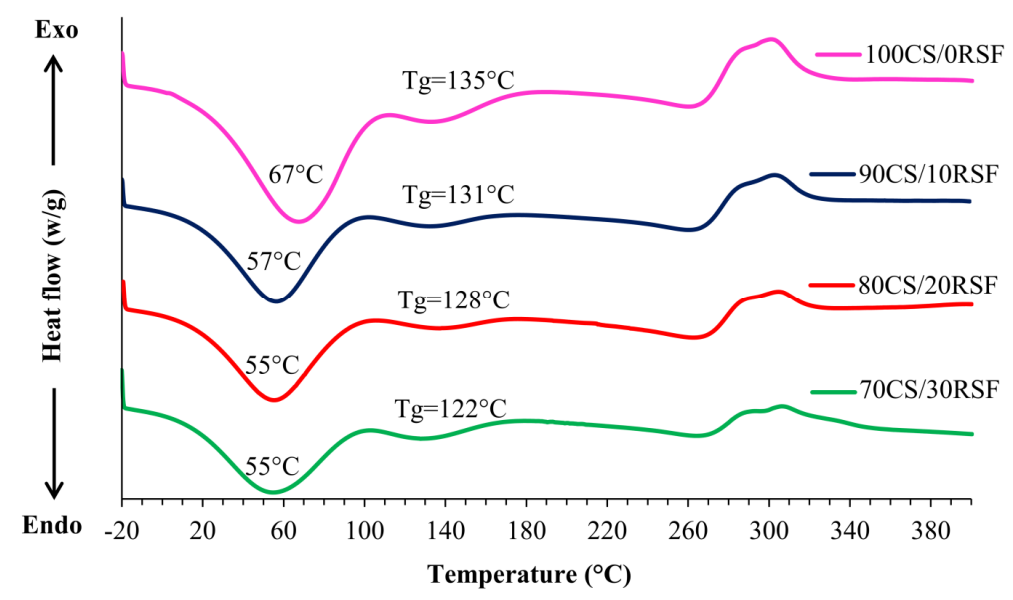

Fig. 3: DSC curve of CS/RSF films with indicated blend ratios

The $\mathrm{Tg}$ of $100 \mathrm{CS} / 0 \mathrm{RSF}$ film was observed at $135{ }^{\circ} \mathrm{C}$, while 70CS/30RSF film showed Tg at $122^{\circ} \mathrm{C}$. Interestingly, with increasing RSF content, the decreasing $\mathrm{Tg}$ was observed indicating the increased amorphous portion of CS/RSF film [65]. The increasing amorphous fraction could be attributed to a decrease in the film strength. This result was in agreement with their mechanical properties. The Young's modulus of CS/RSF films decreased with increasing RSF content. From DSC peaks, the thermal decomposition temperature of CS/RSF films was $\sim 265-330{ }^{\circ} \mathrm{C}$. The initial thermal decomposition temperature of CS/RSF films slightly increased from 265 to $270{ }^{\circ} \mathrm{C}$ with increasing RSF content indicating that RSF could slightly increase the thermal stability of CS/RSF films.

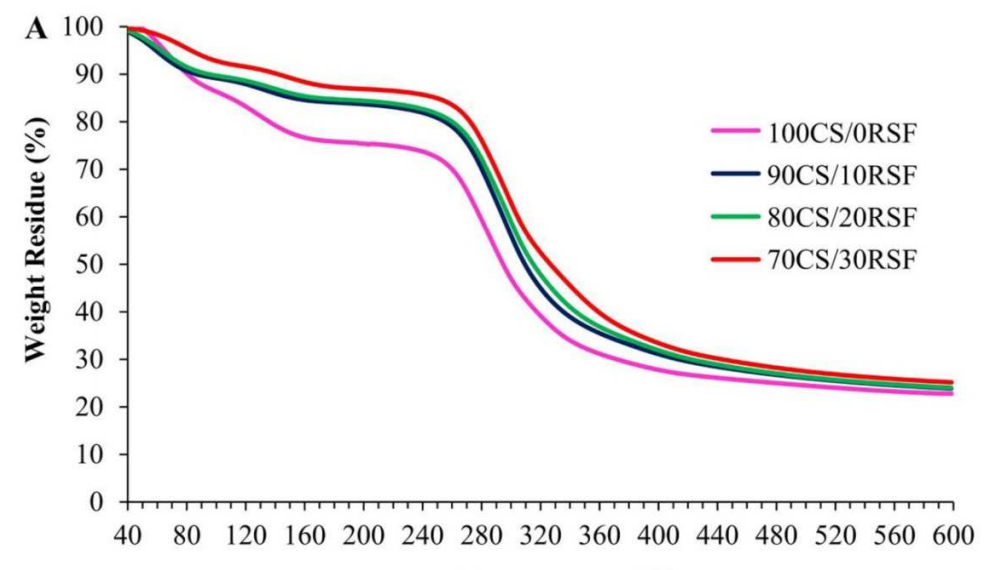

Temperature $\left({ }^{\circ} \mathrm{C}\right)$

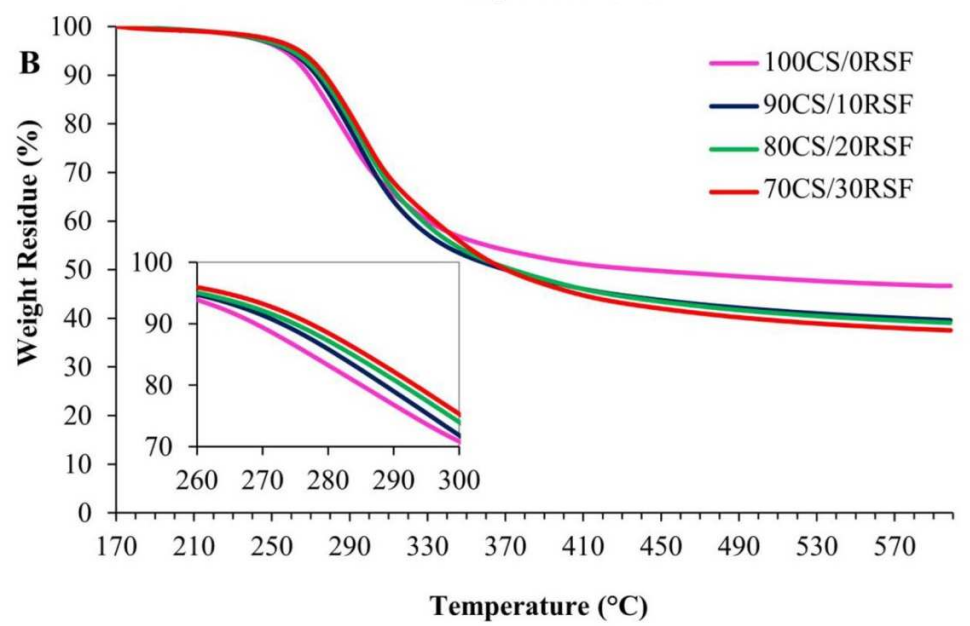

Fig. 4: TGA curve of CS/RSF films with indicated blend ratios, (A) Original curve and (B) Adjusted curve after moisture removal

In addition, the thermal properties of the blended film were also confirmed by TGA. The initial weight loss of CS/RSF films at below $170{ }^{\circ} \mathrm{C}, \sim 5-20 \%$, was due to water evaporation (fig. $4 \mathrm{~A}$ ). In accordance with DSC results, the moisture content of CS/RSF films decreased with increasing RSF contents. However, to determine the effect of RSF content on thermal decomposition temperature, the 
TGA curves of CS/RSF films were adjusted to avoid the interference from the moisture (fig. 4B). The thermal decomposition temperature of CS/RSF films was $\sim 260-330{ }^{\circ} \mathrm{C}$ similar to DSC results. At the thermal decomposition temperature, the residual weight of CS/RSF films slightly increased with increasing RSF. This indicated that increasing RSF slightly increased the thermal stability of CS/RSF films. Furthermore, both DSC and TGA techniques revealed that all CS/RSF films possessed high thermal stability with the thermal decomposition temperature of $>260^{\circ} \mathrm{C}$. This confirmed that CS/RSF films were able to be autoclaved at $121{ }^{\circ} \mathrm{C}$ without deterioration.

\section{Ion permeability of CS/RSF films}

Ion permeability of contact lenses is a critical variable for lens motion on the eye [66]. For sufficient on-eye-movement, typically, ion permeability of the lens should be greater than $12 \times 10^{-6} \mathrm{~mm}^{2} / \mathrm{min}$ [67].
The ion permeability of CS/RSF films was calculated using the slope obtained from the plots of $\mathrm{NaCl}$ concentration in the receiving chamber versus time (fig. 5). The ion permeability of 100CS/0RSF and 70CS/30RSF films showed no significant difference of $10.91 \times 10^{-3}$ and $10.70 \times 10^{-3} \mathrm{~mm}^{2} / \mathrm{min}$, respectively. It is important to note that the ion permeability of CS/RSF films showed approximately 900 times higher than that of the minimum ion permeability requirement. Interestingly, comparing to commercial soft contact lenses, the ion permeability of CS/RSF films was likely an intermediate range of the ion permeability of various commercial contact lenses $(0.6$ to $26 \times 10^{-3} \mathrm{~mm}^{2} / \mathrm{min}$ ) [50]. In general, the contact lens material with high water content usually gives high ion permeability. As a consequence, CS/RSF films showed high water content (59 to $65 \%$ by weight) that could lead to ion permeability enhancement.

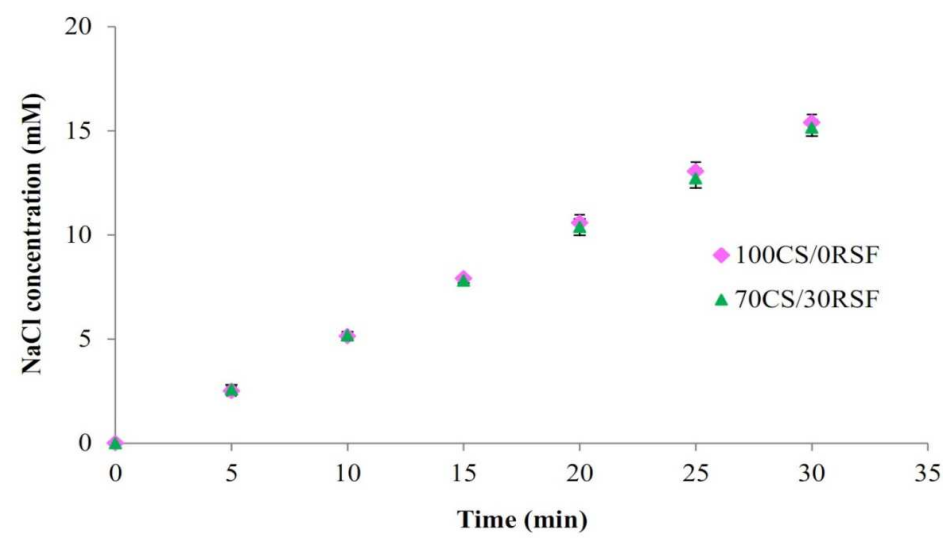

Fig. 5: The plots of $\mathrm{NaCl}$ concentration in the receiving chamber versus time for CS/RSF films used in ion permeability study, error bars indicate SD for $n=3$

\section{Oxygen permeability of CS/RSF films}

Oxygen permeability is an important parameter to characterize the contact lenses. Contact lenses with high oxygen permeability to the cornea tend to be safer, lower the risk of corneal hypoxia, and provide greater comfort of wearing. 100CS/0RSF and 70CS/30RSF contact lenses were successfully prepared by spinning casting method with $0.2 \mathrm{~mm}$ in thickness. The oxygen permeability of $100 \mathrm{CS} / 0 \mathrm{RSF}$ contact lenses was 22 Barrers $\left(10^{-11}\right.$ $\left.\left(\mathrm{cm}^{2} / \mathrm{sec}\right)\left(\mathrm{mlO}_{2}(\mathrm{ml} \times \mathrm{mmHg})\right)\right)$. In contrast, the $70 \mathrm{CS} / 30 \mathrm{RSF}$ contact lenses showed greater oxygen permeability of 26 Barrers. This result indicated that oxygen permeability of CS/RSF films slightly increased with higher amount of RSF because it could be strongly related to the polymorphism of the film [68]. As evident from DSC results, the amorphous portion of CS/RSF films slightly increased with increasing RSF content. Accordingly, oxygen permeability of CS/RSF contact lenses were shown to meet standards for use as daily disposable contact lenses as compared to the commercial contact lenses (10-33 Barrers) [20, 64].

\section{In vitro enzymatic degradation study}

Enzymatic degradation is a significant consideration in the design and quality control of the soft contact lenses materials. Biodegradable materials are not suitable for contact lenses application because the small residual may cause eye irritation. Thus, the stability of CS/RSF film in tear fluids containing important amounts of proteins and lysozyme is a crucial issue. The CS/RSF films are constructed from CS, which can be hydrolysed by the lysozyme presenting in tear fluids. Therefore, the remaining weight of CS/RSF was determined upon their incubation in the STF containing lysozyme. After incubation in the STF containing lysozyme for $14 \mathrm{~d}$, only 70CS/30RSF film showed no degradation with percentage of remaining weight of $100 \%$ (table 4). In contrast, CS/RSF films at ratios of 100/0, 90/10, 80/20 (w/w) illustrated slight degradation as evidenced by from the remaining weight of 94 , 97 , and $99 \%$, respectively. The degradation of CS/RSF films in the STF containing lysozyme increased by increasing the proportion of CS. This result could be attributed to a partial hydrolysis of CS by lysozyme [43, 51]. Nevertheless, all CS/RSF films incubated with STF containing lysozyme for $7 \mathrm{~d}$ showed no degradation, with remaining weight of $100 \%$.

\section{Cytotoxicity study}

The cell viability of HCECs after incubation with CS/RSF films for 24 $\mathrm{h}$ was approximately $100 \%$ (see fig. 6) indicating that CS/RSF films are non-cytotoxic. In addition, non-cytotoxicity of CS/RSF films was further confirmed by microscopic observation (table 5). Upon treatment with CS/RSF films, the appearance of confluence HCECs showed no significant difference as compared to those treated without CS/RSF films (control). Similarly, after they were incubated with MTT, the appearance of HCECs treated with CS/RSF films showed similar morphology as those of control.

Table 4: Percentage of the remaining weight of CS/RSF films after incubation in STF Containing lysozyme

\begin{tabular}{llll}
\hline Mass ratio of CS/RSF (w/w) & \multicolumn{2}{l}{ Remaining weight (\%) \pm SD } & 7 d \\
\cline { 2 - 4 } & $\mathbf{2 d}$ & $\mathbf{5 ~ d ~}$ & $100 \pm 1$ \\
\hline $100 / 0$ & $100 \pm 1$ & $100 \pm 0$ & $100 \pm 1$ \\
$90 / 10$ & $100 \pm 1$ & $100 \pm 1$ & $94 \pm 2$ \\
$80 / 20$ & $100 \pm 0$ & $100 \pm 0$ & $100 \pm 1$ \\
$70 / 30$ & $101 \pm 1$ & $100 \pm 1$ & $100 \pm 1$ \\
\hline
\end{tabular}

SD: standard deviation, $n=3$ 
Table 5: Optical micrographs of HCECs after $24 \mathrm{~h}$ incubation with film and after $2 \mathrm{~h}$ incubation with MTT solution ( $\times 4$ magnification)
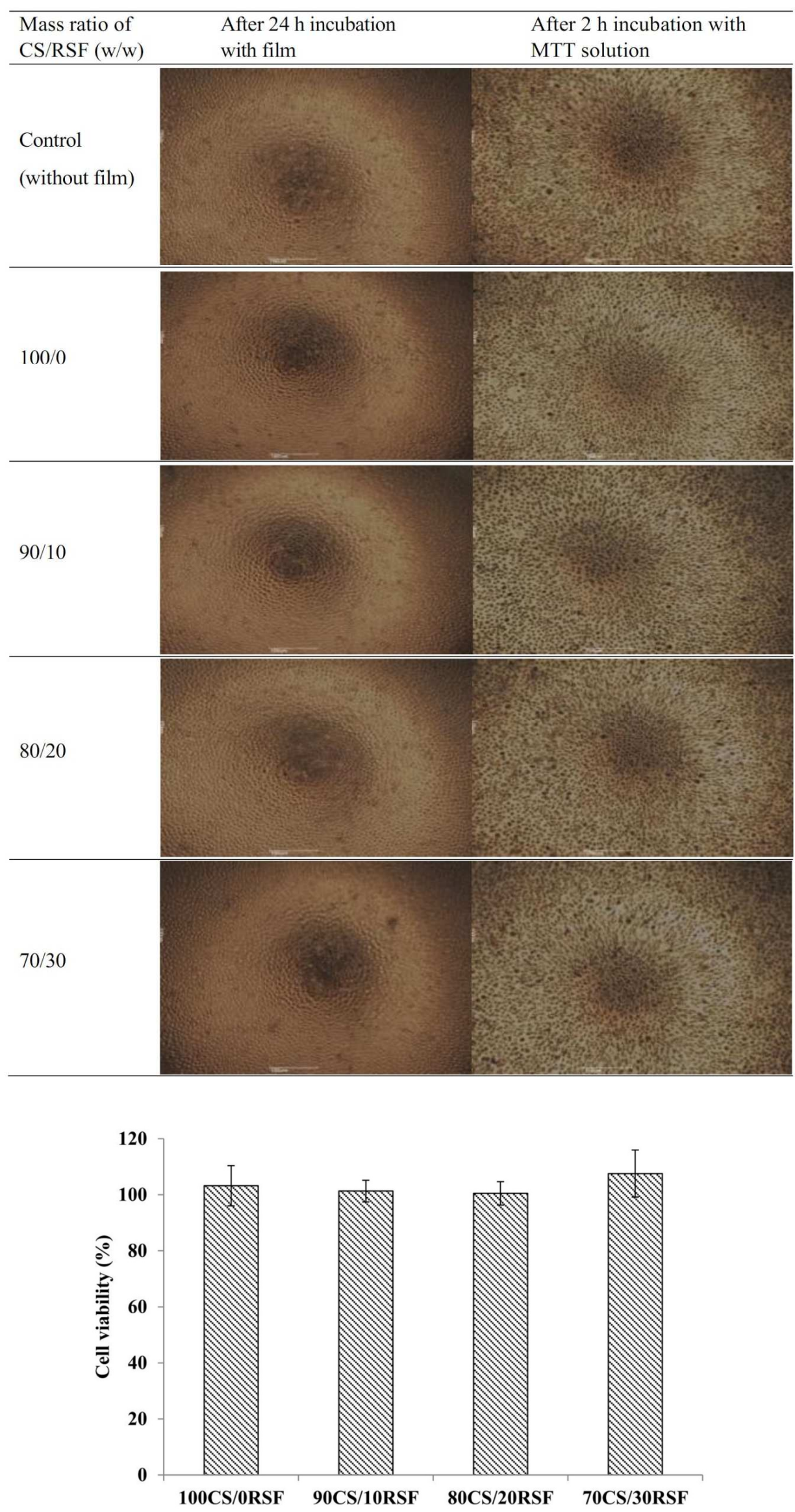

Fig. 6: Cell viability of HCECs after exposed to CS/RSF films for $24 \mathrm{~h}$, error bars indicate SD for $n=3$ 


\section{CONCLUSION}

The CS/RSF films at ratios of 100/0, 90/10, 80/20 and 70/30 $(\mathrm{w} / \mathrm{w})$ showed high visible light transparency, smooth surface morphology and their cross-sections exhibited homogenous blending between CS and RSF without phase separation. With increasing RSF content, oxygen permeability, and thermal stability of the prepared films increased whereas the mechanical properties and water content of the prepared films slightly decreased. Moreover, all prepared films showed high thermal stability, high Young's modulus and elongation at brake. In conclusion, all prepared films were softness with high strength characteristics, good oxygen and ion permeability, high water content, no cytotoxicity and no degradation in STF containing lysozyme for $7 \mathrm{~d}$ implying that prepared films were biocompatible and could promote the comfort for wearing without irritation and grittiness in the eyes. Therefore, CS/RSF films showed excellent physicochemical properties and non-cytotoxicity indicating their promising potential use as a biomaterial for daily disposable contact lenses-based ophthalmic drug delivery system.

\section{ACKNOWLEDGMENT}

The authors acknowledge the financial support by Naresuan University (Grant No. R2559C225) and Thailand Research Fund (TRF) under the Royal Golden Jubilee Ph. D. Program (Grant No. PHD/0044/2557). This research is also partially supported by the Center of Excellence for Innovation in Chemistry (PERCH-CIC), Commission on Higher Education, Ministry of Education, Thailand. We are grateful to Associate Professor Dr. Sangly P. Srinivas, School of Optometry, Indiana University, USA for providing HCECs. We are also thankful to Mettler-Toledo (Thailand) Co., Ltd. for supporting DSC and TGA analysis. Finally, we give a special thanks to Mr. Kenje Baris Gunda, Specialist Lecture, Naresuan University Language Centre, who read and edited the entire manuscript fixing many grammatical and typographical error.

\section{AUTHORS CONTRIBUTIONS}

All the author have contributed equally

\section{CONFLICT OF INTERESTS}

The author reports no conflicts of interest

\section{REFERENCES}

1. Bourlais CL, Acar L, Zia H, Sado PA, Needham T, Leverge R. Ophthalmic drug delivery systems. Prog Ret Eye Res 1998; 17:33-58.

2. Lang JC. Ocular drug delivery conventional ocular formuations. Adv Drug Delivery Rev 1995;16:39-43.

3. Ali M, Byrne ME. Challenges and solutions in topical ocular drug delivery systems. Expert Opin Drug Delivery 2008;1:145-61.

4. Deshpande SG, Shirolkar S. Sustained release ophthalmic formulations of pilocarpine. Pharm Pharmacol 1989;41:197-200.

5. Geroski DH, Edelhauser HF. Drug delivery for posterior segment eye disease. Invest Ophthalmol Vis 2000;41:961-4.

6. Hyun JJ, Anuj C. Ophthalmic drug delivery by contact lenses. Expert Rev Ophthalmol 2012;7:199-201.

7. Winfield AJ, Jessiman D, Williams A, Esakowitz L. A study of the causes of non-compliance by patients prescribed eyedrops. Br J Ophthalmol 1990;74:477-80.

8. Barbu E, Verestiuc L, Nevell TG, Tsibouklis J. Polymericmaterials for ophthalmic drug delivery: trends and perspectives. J Mater Chem 2006;16:3439-43.

9. Lin HR, Sung KC. Carbopol/pluronicphasechange solutions for ophthalmic drug delivery.J Controlled Release 2000;69:379-88.

10. Maulvi FA, Soni TG, Shah DO. A review on therapeutic contact lenses for ocular drug delivery. Drug Dev 2016;23:3017-26.

11. Xinming L, Yingde C, Lloyd AW, Mikhalovsky SV, Sandeman SR, Howel CA, et al. Polymeric hydrogels for novel contact lensbased ophthalmic drug delivery systems: a review. Cont Lens Anterior Eye 2008;31:57-64.

12. Guzman Aranguez A, Colligris B, Pintor J. Contact lenses: promising devices for ocular drug delivery. Ocul Pharmacol Ther 2013;29:189-99.

13. Gulsen D, Chauhan A. Dispersion of microemulsion drops in HEMA hydrogel: a potential ophthalmic drug delivery vehicle. Int J Pharm 2005;292:95-117.
14. Tieppo A, Pate KM, Byrne ME. In vitro controlled release of antiinflammatory from daily disposable therapeutic contact lenses under physiological ocular tear flow. Eur J Pharm Biopharm 2012;81:170-7.

15. Karlgard CCS, Wong NS, Jones LW, Moresoli C. In vitro uptake and release studies of ocular pharmaceutical agents by siliconcontaining and p-HEMA hydrogel contact lens materials. Int J Pharm 2003;257:141-51.

16. Zhu Q, Mao S. Enhanced drug loading efficiency of contact lenses via salt-induced modulation. Asian J Pharm Sci 2019;14:204-15.

17. McDermott ML, Chandler JW. Therapeutic uses of contact lenses. Surv Ophthalmol 1989;33:381-94.

18. Henry VA, DeKinder JO. Soft lens material selection. In: Bennett ES, Henry VA. ed. Clinical manual of contact lenses. $4^{\text {th }}$ ed: Lippincott, Williams, and Wilkins; 2014.

19. Lloyd AW, Faragher RGA, Denyer SP. Ocular biomaterials and implants. Biomaterials 2001;22:769-85.

20. Lee SE, Kim SR, Park M. Oxygen permeability of soft contact lenses in different $\mathrm{pH}$, osmolality and buffering solution. Int J Ophthalmol 2015;8:1037-42.

21. Alava J, Garagorri N, Briz N, Mendicute J. Effects of bacterial adhesion with respect to the type of material, structure and design of intraocular lenses. J Mater Sci Mater Med 2005;16:313-7.

22. Tighe BJ. A decade of silicone hydrogel development: surface properties, mechanical properties, and ocular compatibility. Eye Contact Lens 2013;39:4-12.

23. Horst CR, Brodland B, Jones LW, Brodland GW. Measuring the modulus of silicone hydrogel contact lenses. Optom Vis Sci 2012;89:1468-76.

24. Ho CH, Hlady V. Fluorescence assay for measuring lipid deposits on contact lens surfaces. Biomaterials 1995;16:479-82.

25. Fornasiero F, Prausnitz JM, Radke CJ. Post-lens tear-film depletion due to evaporative dehydration of a soft contact lens. J Membrane Sci 2006;275:229-43.

26. Minoura N, Tsukada M, Nagura M. Fine structure and oxygen permeability of silk fibroin membrane treated with methanol. Polymer 1990;31:265-9.

27. Minoura N, Tsukada M, Nagura M. Physico-chemical properties of silk fibroin membrane as a biomaterial. Biomaterials 1990;11:430-4.

28. Sashina ES, Golubikhin AY, Novoselov NP, Tsobkallo ES, Zaborskii M, Goralskii Y. Study of a possibility of applying the films of the silk fibroin and its mixtures with synthetic polymers for creating the materials of contact lenses. Russ J Appl Chem 2009;82:898-904.

29. Liu TL, Miao JC, Sheng WH, Xie YF, Huang Q, Shan YB, et al. Cytocompatibility of regenerated silk fibroin film: a medical biomaterial applicable to wound healing. J Zhejiang Univ Sci B 2010;11:10-6.

30. Ju HW, Lee OJ, Lee JM, Moon BM, Park HJ, Park YR, et al. Wound healing effect of electrospun silk fibroin nanomatrix in burnmodel. Int J Biol Macromol 2016;85:29-39.

31. Li M, Lu S, Wu Z, Tan K, Minoura N, Kuga S. Structure and properties of silk fibroin-poly (vinyl alcohol) gel. Int J Biol Macromol 2002;30:89-94.

32. Caner C, Vergano PJ, Wiles JL. Chitosan film mechanical and permeation properties as affected by acid, plasticizer, and storage. J Food Sci 1998;63:1049-53.

33. Luangbudnark W, Viyoch J, Laupattarakasem W, Surakunprapha P, Laupattarakasem P. Properties and biocompatibility of chitosan and silk fibroin blend films for application in skin tissue engineering. Sci World J 2012;2012:697201.

34. Kweon H, Ha HC, Um IC, Park YH. Physical properties of silk fibroin/chitosan blend films. J Appl Polym Sci 2001;80:928-34.

35. Shi XY, Tan TW. New contact lens based on chitosan/gelatin composites. J Bioact Compat Pol 2004; 19:467-79.

36. Dalia MNA, Ahmed Abd Eb, Samia HS, Mohamed AEN. Chitosan mucoadhesive buccal films: effect of different casting solvents on their physicochemical properties. Int J Pharm Pharm Sci 2016;8:206-13.

37. Preethi GB, Prashanth K. Design and evaluation of controlledrelease ocular inserts of brimonidine-tartrate and timolol maleate. Int J Pharm Pharm Sci 2016;9:79-82. 
38. Aya MD, Hamdy MD, Amal SMAE-e, Maha KAK. Fabrication of bioadhesive ocusert with different polymers: Once a day dose. Int J Appl Pharm 2018;10:309-17.

39. Moraes MAd, Nogueira GM, Weska RF, Beppu MM. Preparation and characterization of Insoluble silk fibroin/chitosan blend films. Polymers 2010;2:719.

40. Sashina ES, Janowska G, Zaborski M, Vnuchkin AV. Compatibility of fibroin/chitosan and fibroin/cellulose blends studied by thermal analysis. J Therm Anal Calorim 2007;89:887-91.

41. Bini E, Knight DP, Kaplan DL. Mapping domain structures in silks from insects and spiders related to protein assembly. J Mol Biol 2004;335:27-40.

42. Mukhamedzhanova MY, Takhtaganova DB, Pak TS. Properties of concentrated solutions of fibroin and its derivatives. Chem Nat Compd 2001;37:377-80.

43. Verheul RJ, Amidi M, van Steenbergen MJ, van Riet E, Jiskoot W, Hennink WE. Influence of the degree of acetylation on the enzymatic degradation and in vitro biological properties of trimethylated chitosans. Biomaterials 2009;30:3129-35.

44. Yamada H, Nakao H, Takasu Y, Tsubouchi K. Preparation of undegraded native molecular fibroin solution from silkworm cocoons. Mater Sci Eng 2001;14:41-6.

45. Akiyoshi A. Dissolution of silk fibroin with calcium chloride/ethanol aqueous solution. J Sericol Sci Japan 1998;67:91-4.

46. Kim KM, Son JH, Kim SK, Weller C, Hanna M. Properties of chitosan films as a function of $\mathrm{pH}$ and solvent type. J Food Sci 2006;71:119-24.

47. Peng CC, Kim J, Chauhan A. Extended delivery of hydrophilic drugs from silicone-hydrogel contact lenses containing vitamin E diffusion barriers. Biomaterials 2010;31:4032-47.

48. Tranoudis I, Efron N. Tensile properties of soft contact lens materials. Cont Lens Anterior Eye 2004;27:177-91.

49. Jung HJ, Abou Jaoude M, Carbia BE, Plummer C, Chauhan A. Glaucoma therapy by the extended release of timolol from nanoparticle loaded silicone-hydrogel contact lenses. J Controlled Release 2013;165:82-9.

50. Gavara R, Compan V. Oxygen, water, and sodium chloride transport in soft contact lenses materials. J Biomed Mater Res B Appl Biomater 2017;105:2218-31.

51. Chaiyasan W, Srinivas SP, Tiyaboonchai W. Mucoadhesive chitosan-dextran sulfate nanoparticles for sustained drug delivery to the ocular surface. J Ocul Pharmacol Ther 2013;29:200-7.

52. Nwe N, Furuike T, Tamura H. The mechanical and biological properties of chitosan scaffolds for tissue regeneration templates are significantly enhanced by chitosan from gongronella butleri. Materials 2009;2:374-98.
53. She Z, Zhang B, Jin C, Feng Q, Xu Y. Preparation and in vitro degradation of porous three-dimensional silk fibroin/chitosan scaffold. Polym Degrad Stabil 2008;93:1316-22.

54. Gorbet MB, Tanti NC, Jones L, Sheardown H. Corneal epithelial cell biocompatibility to silicone hydrogel and conventional hydrogel contact lens packaging solutions. Mol Vis 2010;16:272-82.

55. Takara EA, Marchese J, Ochoa NA. NaOH treatment of chitosan films: Impact on macromolecular structure and film properties. Carbohydr Polym 2015;132:25-30.

56. Lai CF, Li JS, Fang YT, Chien CJ, Lee CH. UV and blue-light antireflective structurally colored contact lenses based on a copolymer hydrogel with amorphous array nanostructures. RSC Adv 2018;8:4006-13.

57. Gonzalez Meijome JM, Compan Moreno V, Riande E. Determination of oxygen permeability in soft contact lenses using a polarographic method: estimation of relevant physiological parameters. Ind Eng Chem Res 2008;47:3619-29.

58. Vasconcelos A, Freddi G, Cavaco Paulo A. Biodegradable materials based on silk fibroin and keratin. Biomacromolecules 2008;9:1299-305.

59. Edwin K, Yuansheng Z, Yongchun Z. Analysis of the secondary crystalline structure of regenerated Bombyx mori fibroin. Res Rev Biosci 2013;7:76-83.

60. Ha SW, Tonelli AE, Hudson SM. Structural studies of Bombyx mori silk fibroin during regeneration from solutions and wet fiber spinning. Biomacromolecules 2005;6:1722-31.

61. Rusa CC, Bridges C, Ha SW, Tonelli AE. Conformational changes induced in Bombyx mori silk fibroin by cyclodextrin inclusion complexation. Macromolecules 2005;38:5640-6.

62. Kweon H, Um IC, Park YH. Structural and thermal characteristics of Antheraea pernyi silk fibroin/chitosan blend film. Polymer 2001;42:6651-6.

63. Wang S, Wang QH, Yang X, Wang LY, Zhu HS. Properties of silk fibroin/poly(ethylene glycol) 400 blend films. Chin J Polym Sci 2003;21:87-91.

64. Selby A, Maldonado Codina C, Derby B. Influence of specimen thickness on the nanoindentation of hydrogels: measuring the mechanical properties of soft contact lenses. J Mech Behav Biomed Mater 2014;35:144-56.

65. Khodaverdi E, Tekie FSM, Amoli SS, Sadeghi F. Comparison of plasticizer effect on thermo-responsive properties of eudragit RS films. AAPS PharmSciTech 2012;13:1024-30.

66. Domschke A, Lohmann D, Winterton L. On-eye mobility of soft oxygen permeable contact lenses. Proceedings of the ACS Spring National Meeting, San Francisco: PMSE; 1997.

67. Nicolson PC, Vogt J. Soft contact lens polymers: an evolution. Biomaterials 2001;2:3273-83.

68. Marelli B, Brenckle MA, Kaplan DL, Omenetto FG. Silk fibroin as an edible coating for perishable food preservation. Sci Rep 2016;6:25263. 